\title{
Optimisation of composite boat hulls using first principles and design rules
}

\author{
A.J.Sobey ${ }^{*}$,, J.I.R.Blake ${ }^{\mathrm{a}}$, R.A.Shenoi ${ }^{\mathrm{a}}$ \\ ${ }^{a}$ Fluid Structure Interactions, University of Southampton, University Rd, Southampton/England, SO17 1BJ, Tel.: +44 (0)2380 597773
}

\begin{abstract}
The design process is becoming increasingly complex with designers balancing societal, environmental and political issues. Composite materials are attractive to designers due to excellent strength to weight ratio, low corrosion and ability to be tailored to the application. One problem with composite materials can be the low stiffness that they exhibit and as such for many applications they are stiffened. These stiffened structures create a complex engineering problem by which they must be designed to have the lowest cost and mass and yet withstand loads. This paper therefore examines the way in which rapid assessment of stiffened boat structures can be performed for the concept design stage. Navier grillage method is combined with genetic algorithms to produce panels optimised for mass and cost. These models are constrained using design rules, in this case ISO 12215 and Lloyd's Register Rules for Special Service Craft. The results show a method that produces a reasonable stiffened structure rapidly that could be used in advanced concept design or early detailed design to reduce design time.
\end{abstract}

Key words: Structural Optimisation, Composite Grillages, Concept Design, Genetic Algorithm, Analytical Modelling

\section{NOMENCLATURE}

\section{Introduction}

The design process is becoming increasingly complex as more subsystems of design must be taken into account and the opinions of production engineers, supply chain partners and company strategists are sought to improve products. Pressure to relate to more parts of the core business than ever before increases the need for design engineers to understand other dimensions of design. While it is important to understand other dimensions of design it is impractical to retrain design engineers in these different roles and therefore

\footnotetext{
${ }^{*}$ Corresponding author

Email address: ajs502@soton.ac.uk (A.J.Sobey)
} 
communication between these dimensions must effectively transfer the correct information. Further to problems of communication between different dimensions revolutionary designs are an avenue that will allow companies to remain competitive in an ever more global market. Currently the design process within the boatbuilding industry often relies on evolving a previous design for a new product. As an example this may involve using a previous product and stretching the midships to produce the new design with minimal other changes to the internal scantling arrangement. Aesthetically this helps to build a brand through a similar hull shape and has design advantages that include a rapid design process and safety through the knowledge that the previous design performed safely. However, as well as these advantages are the disadvantages that any inefficiency in the design is passed forwards and there is little room to improve the design over time. In the case of evolutionary design the product continues to be in the same part of the design space with minimal changes between the different versions. In the case of the revolutionary design each design moves in a different direction sometimes moving far from previous designs sometimes coming back to a similar state. It is this ability to move through this design space that gives an optimum design and a competitive advantage to boatbuilders.

One potential solution in trying to produce revolutionary designs, in a short time frame while generating a longer time to discuss design decisions with other dimensions of the company, is the development of design tools. These tools allow the designers to start further into the detailed design stage than starting from a blank sheet of paper allowing a comparative starting point to using a previous design. Furthermore the ability to utilise multiobjective optimisation will also allow a designer to take into account other dimensions and produce revolutionary designs. This is particularly difficult in the area of composite structures which have a large number of variables that can be adapted to produce an optimal design.

The optimisation can be performed with Genetic Algorithms that allow a large search space to be searched across a number of objectives. The disadvantage of this method is that it is slow to produce an answer. There are many available papers discussing optimisation and more specifically genetic algorithms to solve composite design problems. A selection of literature for a range of applications follows. Satheesh et al. [26] looked at the use of multiple failure criteria with genetic algorithms for design optimisation of laminated plates. Kim and Kim[13] looked at the optimal design of stiffened panels from buckling. Kang and Kim [12] looked at minimum weight design of compressively loaded composite plates using nonlinear finite element analysis. Naik et al.[21] used a genetic algorithm to look at maximum stress and Tsai-Wu failure criteria for minimum weight design of composite plates. Lopez et al. [18] investigated the use of optimisation for composites considering maximum stress, Tsai-Wu and Puck failure criteria on a laminated 
plate. While this research as well as many others relates optimisation to composite problems the topologies investigated are not indicative of those found in final products. It will therefore be important to apply the important lessons learnt here to more complex topologies for use in concept design.

Optimisation specific to structures has been carried out over a number of years. One of the first instances of this was by Hughes and Mistree [10], who developed a program to look at large complex ship structures. During the early 1980's work started on multiobjective optimisation trying to include design for production into the optimisation problem as reported in Souther [30], Kuo et al. [15], and this work has continued into this century by Rigo [25] and Klanac and Kujala [14] among others, who looked at the use of optimisation for steel structural topologies. Maneepan [19] looked at optimisation of composite stiffened grillage structures with simplistic failure criteria. Hajirasouliha et al. [7] used iterative design optimisation for design of truss-like structures. More recently Finite Element Analysis (FEA) methods are finding a growing interest with many papers such as Gillet et al. [6] and Forrester et al. [4] among many others representing this interest. However its high computational expense, even when combined with surrogate modelling, limits its application within early design. The next steps in structural optimisation are the development of codes which cope with an increased number of variables and search spaces as shown in Gillet et al. [6] who states that "the designer is often obliged to settle for a set of parameters so as to reduce the optimization problem's level of complexity".

To counteract these problems this paper therefore looks at the use of a rapid structural analysis method, Navier Grillage theory, as a method to analyse structures for advanced concept design into early detailed design. The authors optimise a composite grillage panel using design rules to show the possibilities of the method and a first principles method for academic interest. This method will allow designers a starting point for their design that can be taken on to incorporate those dimensions that rely on models that are computationally expensive or qualitative. This is achieved at a level of accuracy useful for early design without the requirement to resort to expensive FEA techniques. It is not the intent of the authors to remove the designer from the loop but to allow them the ability to replace previous designs with revolutionary solutions to be taken forward in the design process.

\section{Structural Modelling}

An embedded genetic algorithm has been used in the optimisation process as shown in Figure 1 and developed from [2]. The main genetic algorithm is used to optimise the stiffener spacing in the longitudinal and transverse directions, the material type and layup angles. The embedded algorithm is used to determine 
the optimal geometry of the stiffeners through creation of the crown width and thickness as well as the web height and thickness. This means that the embedded algorithm will develop an optimal stiffener geometry, with respect to mass and cost, for each given stiffener spacing and material property generated in the main algorithm. The main algorithm will then determine the reaction for the total grillage and compare these grillages over many generations until the optimal topology is found.

\subsection{Grillage Method}

The grillage analysis, found in Clarkson [1], uses the Navier summations of points within the grillage to develop the deflection of the stiffeners, and hence the stresses, the topology of which is shown in Figure 2

In the results the values of the wave numbers, $m$ and $n$, have been kept at 11 as this gave fast computational times while being very close to the point of convergence. The equation giving deflection of the stiffened plate can be seen in Eq. (1) and is a double summation dependent on the wave numbers

$$
w(x, y)=\sum_{m=1}^{\infty} \sum_{n=1}^{\infty} a_{m n} \sin \frac{m \pi x}{L} \sin \frac{n \pi y}{B}
$$

where the value of $a_{m n}$ is a coefficient found from Eq.(2). The coefficient $a_{m n}$ is dependent on the flexural rigidities in each longitudinal beam or transverse girder $\left(\mathrm{D}_{s}\right)$ found using elastic equivalent properties.

$$
a_{m n}=\frac{16 P L B}{\pi^{6} m n\left\{m^{4}(g+1) \frac{D_{g}}{L^{3}}+n^{4}(b+1) \frac{D_{b}}{B^{3}}\right\}}
$$

The moments can be found in the beams or girders $\left(\mathrm{M}_{s}\right)$ from Eq. (3):

$$
M_{s}=-D_{s} \frac{\partial^{2} w}{\partial x^{2}}
$$

The shear force can also be found for the beams and girders $\left(\mathrm{Q}_{s}\right)$ from Eq. (4)

$$
Q_{s}=\frac{\partial M_{s}}{\partial x}
$$

Finally, using the maximum moments and shear force in the grillage the maximum stress $\sigma_{\max }$ and shear stress $\tau_{s}$ can be determined as shown in Eqs. (5) and (6), where $\mathrm{E}_{s(i)}$ is the longitudinal modulus of elasticity of the element of a stiffener, $\mathrm{M}_{s}$ is the moment created in the stiffener, $\mathrm{d}_{n a}$ is the vertical distance of the centroid of an element to the neutral axis, $\mathrm{D}_{s}$ is the structural rigidity of a stiffener and $\mathrm{Q}_{s}$ is the shear force in the stiffener:

$$
\begin{aligned}
& \sigma_{\text {max }}=\frac{E_{s(i)} M_{s} d_{n a}}{D_{s}} \\
& \tau_{s}=\frac{E_{s(i)} Q_{s}}{D_{s}} \int_{0}^{s} d_{n a} d s
\end{aligned}
$$




\subsection{Third Order Shear Deformation Theory (TSDT)}

Grillage methods find the maximum stresses in the stiffeners by assuming that the entire load is passed through to the stiffening members. It is also important to make sure that the plates of the hull are thick enough to withstand the expected loads. This can be performed computationally inexpensively using classical laminate plate theory and first order shear deformation theory for single plies. As more layers are required it is necessary to use higher order shear deformation theories but these are computationally more expensive. Plate analysis has been calculated using TSDT [24] to determine the stresses and strains required for the failure criteria as this will allow the full benefits of using different layups in the material to be used.

First the boundary conditions for a plate can be defined from Eqs.(7) to (11):

$$
\begin{aligned}
& u_{0}(x, y)=\sum_{n=1}^{\infty} \sum_{m=1}^{\infty} U_{m n} \cos \alpha x \sin \beta y \\
& v_{0}(x, y)=\sum_{n=1}^{\infty} \sum_{m=1}^{\infty} V_{m n} \sin \alpha x \cos \beta y \\
& w_{0}(x, y)=\sum_{n=1}^{\infty} \sum_{m=1}^{\infty} W_{m n} \sin \alpha x \sin \beta y \\
& \phi_{x}(x, y)=\sum_{n=1}^{\infty} \sum_{m=1}^{\infty} X_{m n} \cos \alpha x \sin \beta y \\
& \phi_{y}(x, y)=\sum_{n=1}^{\infty} \sum_{m=1}^{\infty} Y_{m n} \sin \alpha x \cos \beta y
\end{aligned}
$$

where each value $\left(\mathrm{U}_{m n}, \mathrm{~V}_{m n}, \mathrm{~W}_{m n}, \mathrm{X}_{m n}\right.$ and $\left.\mathrm{Y}_{m n}\right)$ is a coefficient that must be determined from Eq.(14), $\alpha=\pi m / L$ and $\beta=\pi n / B$. The vertical forces at each point on the plate, $\mathrm{q}(\mathrm{x}, \mathrm{y})$, are determined from Eq.(12):

$$
q(x, y)=\sum_{n=1}^{\infty} \sum_{m=1}^{\infty} Q_{m n} \sin \alpha x \sin \beta y
$$

where $\mathrm{Q}_{m n}$ is the lateral loading on the plate and is given by:

$$
Q_{m n}(z)=\frac{4}{L B} \int_{0}^{L} \int_{0}^{B} q(x, y) \sin \frac{m \pi x}{L} \sin \frac{n \pi y}{B} d x d y
$$

It is then possible to find the coefficients of the boundary conditions using the stiffness matrix [C].

$$
[C][\Delta]=\left|\begin{array}{c}
0 \\
0 \\
Q_{m n} \\
0 \\
0
\end{array}\right| \quad[\Delta]=\left|\begin{array}{c}
U_{m n} \\
V_{m n} \\
W_{m n} \\
X_{m n} \\
Y_{m n}
\end{array}\right|
$$


Where $Q_{m n}=-\frac{16 q_{0}}{\pi^{2} m n}$ for uniform loading and $\mathrm{q}_{0}$ is the load on the plate.

The stresses and strains then allow the use of failure mechanisms to determine whether a given thickness of plate will fail.

\subsection{Failure Criteria}

Further to previous work reported by Sobey et al. [28] failure criteria have been added to the model to more accurately model the strength of the composite materials. The failure criteria used came from the 'World Wide Failure Exercise' (WWFE) [11], [8] and [9]. The choice made for each failure type can be seen from Table 1 and was based upon the findings of the World Wide Failure Exercise. In the cases where a choice could be made between a conservative and unconservative estimate it has been decided to use a conservative estimate. This will lead to thicker hull designs but will ensure the safety of the vessel and therefore allows a fair comparison with design rules. Different failure criteria have been compared by Soden et al. [29]. This shows that a minimum of three criteria ensures that at least one of the proposed criteria for each type of failure has been used and these have been outlined in the World Wide Failure Exercise [29] and included in Table 1

The exercise concluded that in the case of buckling criteria that they 'did not address the prediction of buckling modes of failure' [29]. Buckling is a key part of failure in hull stiffeners and therefore an Euler based rule, seen in Eq. (15), where the crown and web are assumed to be taken as clamped at both ends has been used to constrain the model for both the crown and the webs and is taken from [5].

$$
\sigma_{c r i, w e b}=\frac{6.97 \pi^{2} E_{s}}{12\left(1-v_{12}^{2}\left(d_{s} / c_{s}\right)^{2}\right)}, \quad \sigma_{\text {cri,crown }}=\frac{6.97 \pi^{2} E_{s}}{12\left(1-v_{12}^{2}\left(a_{s} / b_{s}\right)^{2}\right)}
$$

Furthermore an arbitrary deflection criteria of $10 \%$ of the length has been included to ensure that materials with a low stiffness and cost cannot be selected without creating a thicker topology.

\subsubsection{Puck Failure Criteria}

The Puck failure criterion is based upon 3-D phenomenological models, which are based on experimental observations. The method is a composite laminate theory method which is nonlinear to solve. The Puck method is recommended by the World Wide Failure Exercise to be used for predicting strength of unidirectional laminae and this method has been used as it gives a more conservative view for the failure of the laminates. Puck's formulation is also used for predicting the initial strength of multidirectional laminates as other methods did not predict the failure very well. Puck is further recommended to be used to predict final strength of multidirectional laminates. 


\subsubsection{Zinoviev Failure Criteria}

The Zinoviev failure criterion is based on the development of maximum stress theory. This method is based on composite laminate theory and has a linear solution. Zinoviev is recommended by the World Wide Failure Exercise to predict the deformation of laminates along with a non-linear method such as Puck.

\subsubsection{Tsai Failure Criterion}

The Tsai failure criterion is developed through an interactive progressive quadratic failure criterion. This method is also based on composite laminate theory and is linear in its solution. The Tsai failure criteria are used in conjunction with Puck to determine the response of lamina. The Tsai failure criteria is the best fit to the test data reported in Soden et al. [29] for the behaviour of the laminates. This criterion underestimates the failure stress at given points and so the Puck failure criterion can be used to check that failure does not occur.

$$
\left(\frac{\sigma_{1}}{X_{T} X_{C}}\right)^{2}+\left(\frac{\sigma_{2}}{Y_{T} Y_{C}}\right)^{2}+\left(\frac{1}{X_{T}}-\frac{1}{X_{C}}\right) \sigma_{1}+\left(\frac{1}{Y_{T}}-\frac{1}{Y_{C}}\right) \sigma_{2}+\left(\frac{2 F_{1} 2 \sigma_{1} \sigma_{2}}{\sqrt{X_{T} X_{C} Y_{T} Y_{C}}}\right)+\left(\frac{\tau_{12}}{S_{12}}\right)^{2}=1
$$

Where $F_{1}$ is the normalized interaction term of the quadratic failure criterion and must be found for the material being tested but is between -1 and 1 for closed envelopes.

\subsection{Cost Model}

To determine the cost accurately it is important to model the production route taken by a material. As hand layup is the method of most prevalence within boatbuilding this technique has been modelled. Production modelling was originally performed using a parametric cost model taken from the Shipbuilders and Shiprepairers Association (SSA) report by Shenoi et al. [27] as shown in Table 4

This model has no cost for stiffeners and is for a sandwich plate. This has therefore meant that a stiffener cost model has been attached to the main model replacing the cutting and laying core section of the SSA production model for each longitudinal and transverse section and shown in table 5

The time for each action has been transformed into a cost by using a wage of $20 £ /$ hour. To determine the raw material costs for the stiffeners cost per kg for each material has been used developed from a database of materials form Lloyds Register is listed in Table 6.

\subsection{Design Rules}

Design rules are the main rules for structural design of hulls used within the boatbuilding community. These rules are based upon first principles and have been developed from years of experience. 


\section{Lloyd's Register}

Lloyd's Register Rules for Special Service Craft is a classification society rule developed for craft over $24 \mathrm{~m}$ in length but sometimes utilised in craft under this length. The rules have a specific set for development of composite structures which allows new materials to be used once the required mechanical properties have been found from experiment. The rules themselves are developed from first principles but with changes made to increase safety based on the use of these rules over time. The composite rules are originally based on those developed from boats constructed from steel.

Determination of the structures are based on defining the boat characteristics and the environment that it is expected that it will be operating in. This can be used to produce a pressure value dependent upon the position of the panel within the hull form. The panel thickness is then defined using this pressure and the distance separating the stiffeners. The stiffener geometry is determined from minimum thickness criteria and determination of the stresses and deflections calculated. These can be compared to stress limits and deflection limits dependent upon the position of the panel.

\section{ISO 12215-5}

ISO $11215-5$ is a newer standard for scantling determination developed for recreational craft under $24 \mathrm{~m}$. These rules also have a specific section for composite materials allowing determination of materials through testing. The rules were developed to reduce the scantling size of smaller recreational craft and to be easily used by structural designers.

The determination of the structures using ISO 12215-5 is similar to that for Lloyd's Register Rules. The pressure is determined from the conditions and the characteristics of the boat. The panel thickness is determined from the pressure, the stiffener spacing and the expected stress; which allows for a less conservative estimate of the hull thickness. The stiffeners are determined through assessing the stresses found to ensure that they do not fail but are further constrained by ratio limits between sections of the stiffeners, a minimum web area and section modulus.

\section{Model Verification}

\subsection{Structural Verification}

Verification of both parts, Navier grillage analysis and TSDT, of the first principles structural analysis method was performed. The results from the grillage method have been compared to the box stiffened structure found in Clarkson [1] for a steel panel with a length and width of $3810 \mathrm{~mm}$. The panel consisted 
of 4 transverse beams and longitudinal girders with approximate dimensions of $254 \mathrm{~mm}$ deep 127 mm wide with $18.288 \mathrm{~mm}$ thick flanges and $9.144 \mathrm{~mm}$ thick webs and a pressure of $137.9 \mathrm{kPa}$ was applied to each panel. The results are presented in Table 7 .

These results were obtained with a wave number of 11, shown in Eq. (1) as $\mathrm{m}$ and $\mathrm{n}$, as it is a value by which the deflection has converged.

These values were found to be close to results found in Maneepan [20] as can be seen in Table 7 Furthermore these values are similar to Clarkson [1], using the folded plate method, which has been compared to experimental results but also remain conservative. The Navier grillage method was therefore used for the stiffener modelling.

A validation of the shear stress has been made in comparison with a theoretical composite rectangular box beam found in Datoo [3] and can be seen in Table 8. The web height is $50 \mathrm{~mm}$ and the flange widths are $200 \mathrm{~mm}$. The Young's modulus of the flanges are $54.1 \mathrm{kN} / \mathrm{mm}^{2}$. The Young's modulus of the web is 17.7 $\mathrm{kN} / \mathrm{mm}^{2}$. A shear force of $\mathrm{Q}=10.0 \mathrm{kN}$ is found in the stiffeners. The thickness of the flanges are $1.0 \mathrm{~mm}$ and the thickness of the web is $0.5 \mathrm{~mm} . \tau_{1}$ is the shear stress at the corner of the crown element, $\tau_{2}$ is the shear stress at the neutral axis of the cross section.

These values had no deviation from the results found in Maneepan and there is only a small deviation found compared to the results found in Datoo. It is therefore considered that the grillage theory is capable of calculating the shear stress.

Finally the elastic equivalent properties were compared to Datoo [3] using lamina properties $\mathrm{E}_{1}=140$ $\mathrm{kN} / \mathrm{mm}^{2}, \mathrm{E}_{2}=10 \mathrm{kN} / \mathrm{mm}^{2}, \mathrm{G}_{12}=5 \mathrm{kN} / \mathrm{mm}^{2}, v_{12}=0.3$ and a ply thickness $=0.125 \mathrm{~mm}$ for each of the 8 plies all having a $0^{\circ}$ ply angle where the result was identical to Datoo's value of $140 \mathrm{GPa}$.

For the verification of TSDT a layup of [0/90/90/0] has been used. The length to width ratio (L/B) of the plate is equal to 1.0 and the length to thickness ratios $(\mathrm{L} / \mathrm{t})$ used are 10, 20 and 100. The material properties are $\mathrm{E}_{1}=175 \mathrm{GPa}, \mathrm{E}_{2}=7 \mathrm{GPa}, \mathrm{G}_{12}=\mathrm{G}_{13}=3.5 \mathrm{GPa}, \mathrm{G}_{23}=1.4 \mathrm{GPa}$, and $v_{12}=v_{13}=0.25$. The load acting on the plate is $\mathrm{q}_{0}=50 \mathrm{kPa}$ and the results of this verification can be seen in Table 9 .

From the validation of the TSDT it is possible to see that the results have at most a $1 \%$ deviation from those given in Reddy at a value for the wave numbers of nine showing TSDT has been modelled accurately.

\subsection{Genetic Algorithm Verification}

Genetic algorithms can be tested to determine if the optimisation that has been carried out reaches the optimum value. This is investigated by starting the algorithm at different points and determining if, at the finish, all the algorithms reach a similar fitness function. The method of genetic algorithms requires that 
the best fitness value, after each generation, will gradually increase. This leads to a distinctive "handgun" shaped graph when the fitness function is plotted against generation. If the same algorithm is started from different points this will lead to the optimisation reaching similar fitness functions as shown in Figure 3

As can be seen from the examples in Figure 3 the graph follows the distinctive genetic algorithm shape where each of the individual strands reaches a similar final result. This shows that the algorithm is working correctly therefore verifying the optimisation.

\section{Plate Analysis}

Minimisation of the different structural models has been carried out to show the results produced from an optimisation using the rapid grillage analysis method. The choice of failure criteria and the structural models for the first principles approach have been introduced. Further to this, ISO 12215-5 and Lloyd's Register Rules for Special Service Craft have been implemented. For each of the different structural models a simple study has been performed on a section of hull. The optimisation was on a grillage panel with a length of $24 \mathrm{~m}$ and a width of $2 \mathrm{~m}$. The length is determined as being the length of the boat so as to fit both Lloyd's Register Rules and ISO 12215-5. For the case of the design rules the pressure has been determined for the bottom of the hull using the calculations provided within the rules. In the case of the Lloyd's register rules this pressure was calculated as $131.47 \mathrm{kPa}$ and for the case of the ISO $12215-5$ this was calculated as $97.31 \mathrm{kPa}$. The first principles rules have been implemented using the pressure from Lloyd's Register Rules for Special Service Craft as this gives the most conservative estimate allowing worst case scenario for the comparison with the structural models. The different properties can vary between different boundaries defined in Table 10 and the material properties for each material shown in Table 11

\subsection{First Principles}

The first principles method has been developed using an amalgamation of all of the failure criteria to constrain the results. The stiffener topology that resulted from optimisation is shown in Table 12 . The plate topology that has been developed is shown in Table 13

The topology has rectangular stiffeners which are widely spaced. This grillage is positioned on a panel that has a small thickness with a material made of E-glass. This therefore means that for the applications within the industry even though the material requires extra mass to be added to the grillage to reduce the deformation of the plate, this is less of a penalty to the mass than the choice of carbon fibre would be to the cost. In comparison to the panels that are developed using design rules the thicknesses of the parts are smaller and the stiffener spacing is much wider. 


\subsection{Lloyd's Register}

A Lloyd's Register Rules for Special Service Craft structural model has been developed and minimised for comparison. This model was developed using Part 5 - Design and Loading Criteria for specification of the pressure and Part 8 - Hull Construction in Composite to determine the topology of the plate. This model has used the code developed to produce a structural topology as shown in Table 14 The topology for the plate assessed using this structural model can be seen in Table 15 .

The topology that has been produced using the Lloyds Register Rules is much thicker than that produced using the first principles methodology. The stiffener spacing is much smaller than that found using the first principles method as can be seen in Tables 13 and 15 Furthermore even with the smaller stiffener size the thickness of the panel is of a much larger size than can be seen with the first principles model, $2.1 \mathrm{~mm}$ larger. This was to be expected as the development of the Lloyd's Register Rules adds safety factors to the values found from first principles to ensure that failure does not occur. As discussed for the first principles model this material selection was the same as found within industry, Eglass/vinylester. The stiffener spacing is developed as the Lloyds Register Rules require a stiffener spacing dependent upon the maximum pressure expected. Furthermore the minimum thickness required under any pressure is $5 \mathrm{~mm}$ and therefore a small increment in thickness above this value for a high pressure is reasonable. The number of plys was 3 as this is the number of plys for a material of up to $9 \mathrm{~mm}$ thick. Finally the stiffener thickness is to be expected due to the large safety factors, 3 times, involved in using Lloyds Register Rules.

\subsection{ISO $12215-5$}

The final method of structural modelling was developed using ISO 12215-5. The resulting stiffener topology for this optimisation can be seen in Table 16 The plate topology for the optimisation can be seen in Table 17

This topology was smaller in terms of mass than that found with the Lloyds register rules optimisation. ISO 12215 is developed for smaller craft, 24m and under, than for Lloyd's Register for Special Service Craft, $24 \mathrm{~m}$ and over, and therefore the rules are for smaller craft resulting in smaller structures. It is therefore expected that the loads on these craft will be smaller. Furthermore ISO 12215-5 has taken into account partial safety factors, as opposed to the phenomological safety factors found in Lloyd's Register Rules, therefore reducing the topology calculated when using these rules. The topology creates a larger mass than for the first principles rules due to the partial safety factors that have been used. These partial safety factors have been made in addition to the first principles in an attempt to reduce the probability of failure to an acceptable 
level for use in leisure boatbuilding. The optimised result for the stiffened shape is triangular unlike the stiffener topology developed for the first principle rules and for Lloyds Register Rules. The resulting plate had thin stiffeners and a thick panel but this is likely from the small stiffener spacing required by the rules. The ply layup consisted of 5 plys with $90^{\circ}$ on the outside and $0^{\circ}$ on the inside. It is a surprising result to have a triangular stiffener as it would have increased the stress due to the low neutral axis. It is premised that this triangular stiffener shape is developed due to the minimum height in comparison to the thickness of the web criteria that is used within ISO 12215-5. A triangular shape is not optimal in terms of height of neutral axis in comparison to the mass required to gain that value. This is no longer true when the height is pre-determined and therefore the triangular shape will reduce the mass as much as possible while still gaining the neutral axis height required. This neutral axis height requirement is further reduced due to the small stiffener spacing produced within the rules.

\section{Discussion}

Having previously developed and verified a first principles structural model, this model has been used to optimise a grillage plate. Two other optimisation procedures have been performed against those using design rules to show the potential for this method to be used in early detailed design. The results for these models can be seen in Figures 4 and 5 which make a comparison based on cost and mass.

From the results it is possible to see that the first principles method produced the lowest combined mass and cost and the Lloyd's Register Rules for Special Service Craft produced the heaviest grillages. This is to be expected as the first principles approach does not contain all of the constraints that would be required for a safe design. It does however exhibit a different style of design from the design rules exhibiting an approach that is worth expanding on in the future to produce more revolutionary designs or one in which a risk based approach could be generated with a specified target reliability. In terms of the design rules Lloyd's Rules for Special Service Craft are designed for larger boats than $24 \mathrm{~m}$ in general and ISO 12215 for those under $24 \mathrm{~m}$. This therefore means that the Lloyd's Rules produce a heavier design as they are generally used with boats seeing higher pressure loadings and do not trend well to this size of design.

The material selection was that of E-glass and this is because the stiffener application does not require a high strength. The stiffness required to ensure that the plate does not have a high deflection can be produced using extra material due to the low cost of the material. This penalty to the mass is less than the potential penalty to the cost of using carbon fibres. It can be seen that the ply angles are not as expected in a real world situation and as such a further improvement could be to optimise the ply angles for the stiffener and the plate 
in a separate genetic algorithm. This would allow a more realistic ply angle and number while also ensuring that the results were closer to an optimum value. It can be seen from the results that all three methods produced panels that are reasonable for the design of a composite grillage. Thin plates were selected with wide stiffeners and thick plates were selected with narrow stiffeners due to the evolutionary design decisions of the genetic algorithm. There is a compromise between a large number of small stiffeners reducing mass or a small number of larger stiffeners to reduce the cost. The implications of these decisions play an important role in the thickness of the hull to ensure that the hull could withstand the loads being applied. The first principles method developed a panel with a thin plate between stiffeners which was unrealistic. It is felt that this method needs more strenuous failure criteria and is not realistic for use within applications.

The panel developed from the optimisation showed two realistic panels, first principles and Lloyd's Register Rules, where ISO 12215 gave an unrealistic stiffener shape. This unrealistic stiffener shape resulted from the rules not constraining the design and the structural model not producing an in-depth enough structural response to determine the failure of this panel. Artificially constraining the base width in this scenario would allow for a successful design for the ISO Rules. The results show that the grillage theory allowed a rapid cost and structural optimisation where satisfactory results could be obtained for an advanced concept or early detailed design. The reduced computational time will allow a virtually unconstrained genetic algorithm to be run allowing the exploration of more revolutionary designs rather than exploring the optimal point around current topologies.

\section{Conclusions}

This paper puts forward a method for structural analysis that allows for the rapid assessment of grillages. This method has been combined with design rules, a cost model and a genetic algorithm to produce a method to allow for more revolutionary designs at the concept design stage. The final results show that the genetic algorithm produces a design that would be usable as a first design. The results show a difference in mass and cost though these may be due to Lloyd's Register Rules for Special Service Craft being designed for large craft and ISO 12215 for smaller designs. The first principles design shows a different design to that produced with the design rules showing that this method may be useful for expanding the creativity of designs in the future but currently requires many more constraints before the design could be concluded as safe.

\section{References}

[1] J. Clarkson. The elastic analysis of flat grillages. Cambridge University Press, 1965. 
[2] D.A. Coley. An introduction to Genetic Algorithms for Scienctists and Engineers. World Scientific, 2001.

[3] M.H. Datoo. Mechanics of Fibrous Composites. Elsevier Science Publishers Ltd., Essex, England, 1991.

[4] A. Forrester, A. Sobester, and A. Keane. Engineering design via surrogate modelling: a practical guide. Chichester, UK, Wiley, 2008.

[5] M.L. Gambhir. Stability analysis and design of structures. Springer, 2004.

[6] A. Gillet, P. Francescato, and P. Saffre. Single- and multi-objective optimization of composite structures: The influence of design variables. Journal of Composite Materials, vol. 44:pp.457-480, 2010.

[7] I. Hajirasouliha, K. Pilakoutas, and H. Moghaddam. Topology optimization for the seismic design of truss-like structures. Computers and Structures, vol. 89:pp.702-711, 2011.

[8] M.J. Hinton, A.S. Kaddour, and P.D. Soden. Evaluation of failure prediction in composite laminates: background to 'part b' of the exercise. Composites Science and Technology, vol. 62:pp.1481-1488, 2002.

[9] M.J. Hinton, A.S. Kaddour, and P.D. Soden. Evaluation of failure prediction in composite laminates: background to 'part c' of the exercise. Composites Science and Technology, vol. 64:pp.321-327, 2004.

[10] O.F. Hughes and F. Mistree. A comprehensive method for the automated opimization of ship structures. In International Symposium on Practical Design in Shipbuilding, Tokyo, pages pp.35-44, 1977.

[11] A.S. Kaddour, M.J. Hinton, and P.D. Soden. A comparison of the predictive capabilities of current failure theories for composite laminates: additional contributions. Composites Science and Technology, vol. 64:pp.449-476, 2004.

[12] J. Kang and C. Kim. Minimum-weight design of compressively loaded composite plates and stiffened panels for postbuckling strength by genetic algorithm. Journal of Composite Materials, vol. 69:pp.239246, 2005.

[13] S. Kim and C. Kim. Optimal design of composite stiffened panel with cohesive elements using microgenetic algorithm. Composite Structures, vol. 44:pp.369-387, 2010. 
[14] A. Klanac and P. Kujala. Optimal design of steel sandwich panel applications in ships. In Proceedings of the ninth symposium of ships and other floating structures. Luebeck-Travemuende, Germany, pages pp.907-914, 2004.

[15] C. Kuo, K.J. MacCallum, and R.A. Shenoi. An effective approach to structural design for production. Trans. of RINA, 1984.

[16] A. Kuraishi, S.W. Tsai, and K.K.S. Liu. A progressive quadratic failure criterion, part b. Composites Science and Technology, vol. 62:pp.1683-1695, 2002.

[17] K. Liu and S.W. Tsai. A progressive quadratic failure criterion for a laminate. Composites Science and Technology, vol. 58:pp.1023-1032, 1998.

[18] R.H. Lopez, M.A. Luersen, and E.S. Cursi. Optimization of laminated composites considering different failure criteria. Composites Part B: Engineering, vol. 40:pp.731-740, 2009.

[19] K. Maneepan. Genetic Algorithm based Optimisation of FRP Composite Plates in Ship Structures. $\mathrm{PhD}$ thesis, University of Southampton, 2007.

[20] K. Maneepan, J.I.R. Shenoi, and J.I.R. Blake. Genetic algorithms (gas) based optimisation of frp composite plated grillages in ship structures. Transactions of The Royal Institution of Naval Architects Part A: International Journal of Maritime Engineering, vol. 149:1-19, 2007.

[21] G.N. Naik, S. Gopalakrishnan, and R. Ganguli. Design optimization of composites using genetic algorithms and failure mechanism based failure criterion. Composite Structures, vol. 69:pp.354-367, 2008.

[22] A. Puck and H. Schurmann. Failure analysis of frp laminates by means of physically based phenomenological models. Composites Science and Technology, vol. 58:pp.1045-1067, 1998.

[23] A. Puck and H. Schurmann. Failure analysis of frp laminates by means of physically based phenomenological models. Composites Science and Technology, vol. 62:pp.1633-1662, 2002.

[24] R.N. Reddy. Mechanics of Laminated Composite Plates and Shells. Second Edition, CRC Press, 2004.

[25] P. Rigo. Least-cost structural optimization oriented preliminary design. Journal of Ship Production, vol. 17:pp.202-215, 2001. 
[26] R. Satheesh, G. Narayan Naik, and R. Ganguli. Conservative design optimization of laminated composite structures using genetic algorithms and multiple failure criteria. Journal of Composite Materials, vol. 44:pp.369-387, 2010.

[27] R.A. Shenoi, J.M Dulieu-Barton, H.K. Jeong, and J.I.R. Blake. Manual of design and production best practice. Technical report, University of Southampton, 2003.

[28] A.J. Sobey, J.I.R. Blake, and R.A. Shenoi. Optimisation approaches to design synthesis of marine composite structures. Schiffstechnik - Ship Technology Research, vol. 56:24-30, 2009.

[29] P.D. Soden, A.S. Kaddour, and M.J. Hinton. Recommendations for designers and researchers resulting from the world-wide failure exercise. Composites Science and Technology, vol. 64:pp.589-604, 2004.

[30] G. Souther. Work content estimating from a ship steelwork database. Trans. of RINA, 1980.

[31] P.A. Zinoviev, S.V. Grigorviev, O.V. Lebedevab, and L.P. Tairova. The strength of multilayered composites under a plane-stress state. Composites Science and Technology, vol. 58, 1998.

[32] P.A. Zinoviev, O.V. Lebedeva, and L.P. Tairova. A coupled analysis of experimental and theoretical results on the deformation and failure of composite laminates under a state of plane stress. Composites Science and Technology, vol. 62:pp.1711-1723, 2002. 
Main Genetic Algorithm:-

Variables: Longitudinal and transverse stiffener spacing's, material type and ply angle. Output: Optimised stiffener spacing and material layup

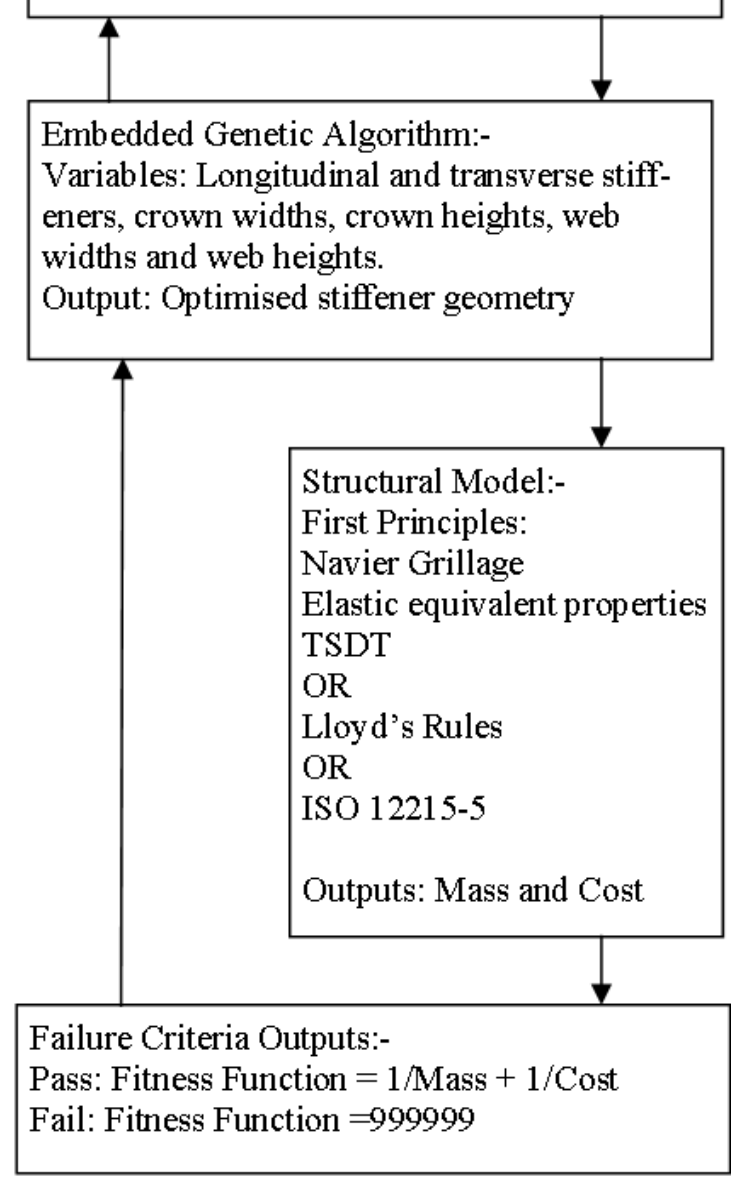

Figure 1: Genetic Algorithm Flow Diagram 


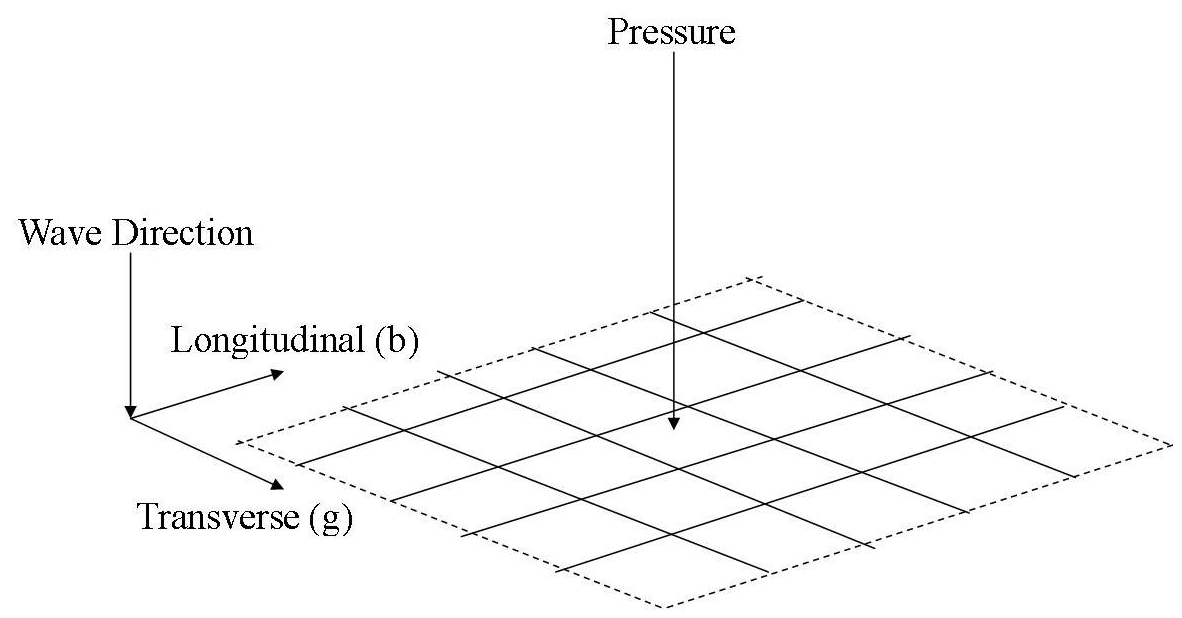

Figure 2: Grillage topology 


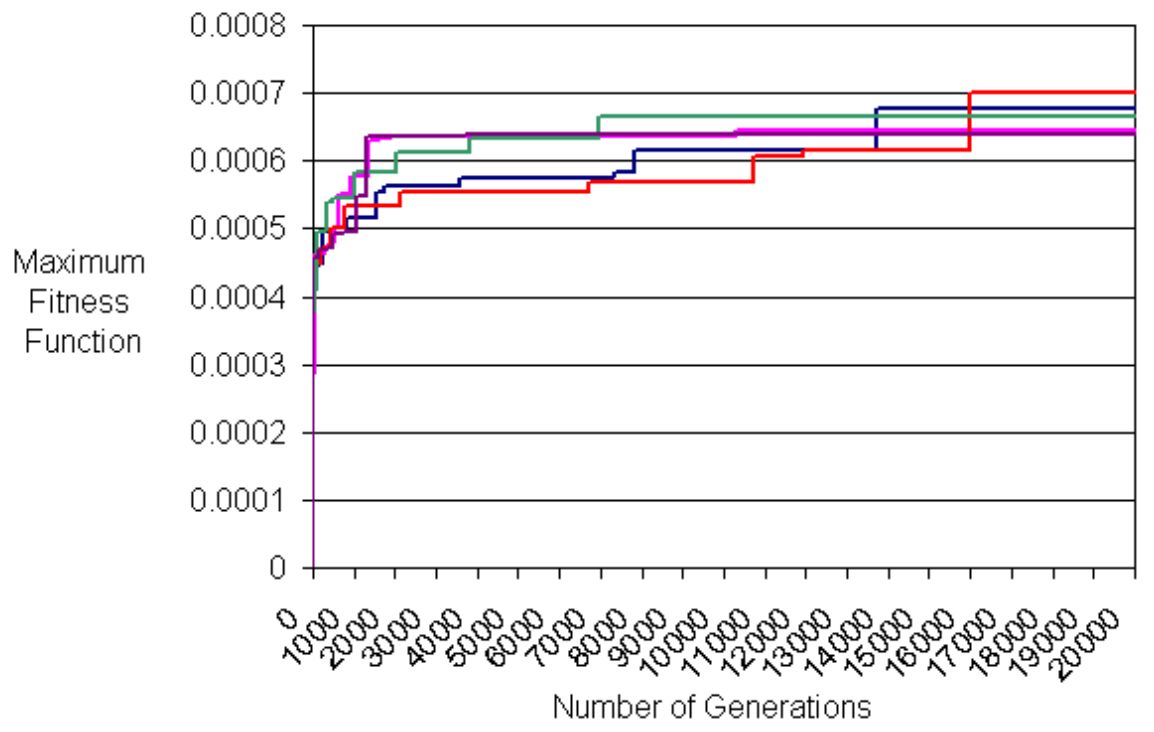

Figure 3: Validation of genetic algorithm using different starting points 


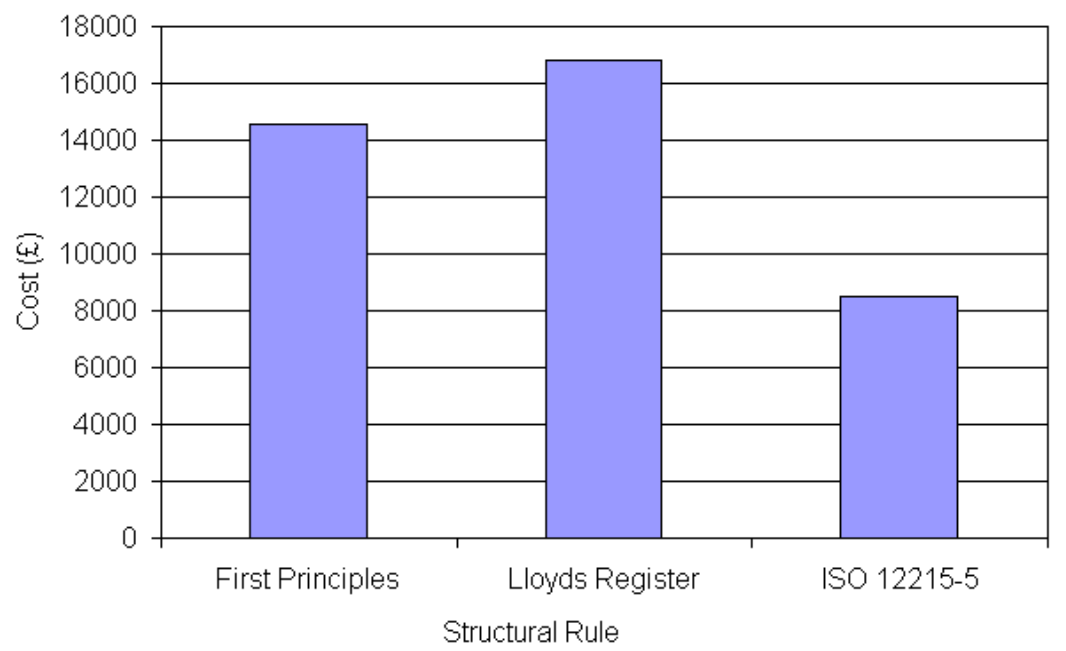

Figure 4: Comparison of cost for structural optimisations 


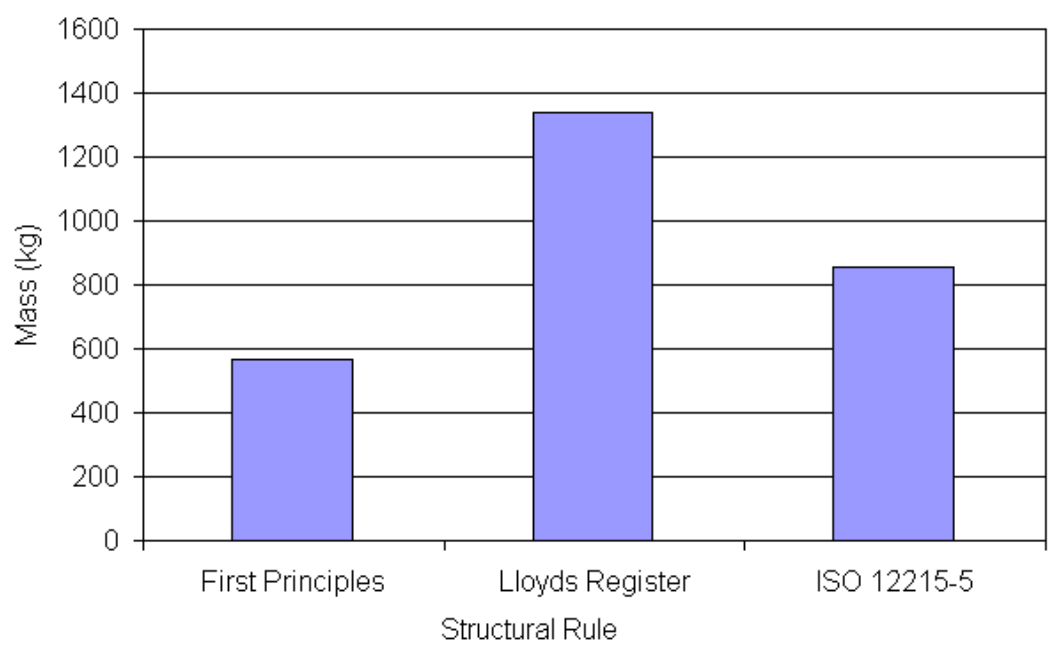

Figure 5: Comparison of mass for structural optimisations 


$\begin{array}{llll}a, b & \text { Stiffener spacing } & \mathrm{n}_{b, g} & \text { Number of beams or girders } \\ \mathrm{a}_{s} & \text { Crown width } & \mathrm{P} & \text { Pressure } \\ \mathrm{a}_{m n} & \text { Coefficient for grillage analysis } & \mathrm{S}_{12} & \text { Shear strength in the 1-2 plane of a ply } \\ \mathrm{A}_{i, j} & \text { Laminate stiffness terms } & \mathrm{t} & \text { Ply thickness } \\ \mathrm{A}_{s x, s y} & \text { Axial rigidities of longitudinal and transverse stiffeners } & \mathrm{U}_{m n}, \mathrm{~V}_{m n}, \mathrm{~W}_{m n}, \mathrm{X}_{m n}, \mathrm{Y}_{m n} & \text { Coefficients for initial conditions } \\ \mathrm{b}_{s} & \text { Crown thickness } & \mathrm{u}_{0}, \mathrm{v}_{0}, \mathrm{~W}_{0}, \phi_{0}, \phi_{0} & \text { Initial conditions of TSDT } \\ \mathrm{b}, \mathrm{g} & \text { Numbers of beams and girders } & \mathrm{w} & \text { Deflection } \\ \mathrm{c}_{s} & \text { Web width } & \bar{w} & \text { Non-dimensionalised deflection } \\ \mathrm{D}_{s x, s y, T x, T y} & \text { Stiffener rigidities } & \mathrm{X}_{C}, \mathrm{X}_{T} & \text { Tensile and compressive strength parallel to fibres } \\ \mathrm{d}_{n a} & \text { Distance of the cross sectional area of stiffeners to the neutral axis } & \mathrm{Y}_{C}, \mathrm{Y}_{T} & \text { Tensile and compressive strength transverse to fibres } \\ \mathrm{d}_{s} & \text { Web height } & \epsilon, \gamma & \text { Stiffness } \\ \mathrm{E} & \text { Young's modulus } & \epsilon_{1 T} & \text { Tensile failure strain } \\ \mathrm{E}_{f 1} & \text { Young's modulus of fibre } & \epsilon_{1 C} & \text { Compressive failure strain } \\ \mathrm{G} & \text { Shear modulus } & \rho_{\perp \|} & \text { Slope of the longitudinal fracture envelope } \\ \mathrm{I} & \text { Second moment of area } & \rho_{\perp \perp} & \text { Slope of the transverse fracture envelope } \\ \mathrm{I}_{c x} & \text { Moment of inertia } & \sigma & \text { Stress } \\ \mathrm{L}, \mathrm{B} & \text { Length and breadth of plate } & \sigma_{c r i} & \text { Critical Stress } \\ \mathrm{M}_{s} & \text { Moments of stiffeners } & \sigma_{1 D} & \text { Stress value for linear degradation } \\ \mathrm{m}, \mathrm{n} & \text { Wave numbers } & \tau & \text { Shear stress } \\ \mathrm{m}_{\sigma f} & \text { Mean stress magnification factor } & v & \text { Poisson's ratio } \\ \mathrm{q}(\mathrm{x}, \mathrm{y}) & \text { Pressure at a given point on plate } & & \end{array}$


Table 1: Failure Criteria

\begin{tabular}{|l|c|}
\hline Failure Type & \multicolumn{1}{|c|}{ Criteria } \\
\hline $\begin{array}{l}\text { Predicting the } \\
\text { response of lamina }\end{array}$ & Puck and Schurmann [22], [23], Liu and Tsai [17] and Kuraishi et al. [16] \\
\hline $\begin{array}{l}\text { Predicting final strength } \\
\text { of multidirectional laminates }\end{array}$ & Puck and Schurmann [22], [23] \\
\hline $\begin{array}{l}\text { Predicting the } \\
\text { deformation of laminates }\end{array}$ & Zinoviev et al. [31], [32] and Puck and Schurmann [22], [23] \\
\hline
\end{tabular}


Table 2: Puck failure criteria

\begin{tabular}{|l|c|}
\hline Fibre failure in tension & \multicolumn{1}{|c|}{$\frac{1}{\epsilon_{1 T}}\left(\epsilon_{1}+\frac{v_{f 12}}{E_{f 1}} m_{\sigma f} \sigma_{2}\right)=1$} \\
\hline Fibre failure in compression & $\left.\frac{1}{\epsilon_{1 C}} \mid\left(\epsilon_{1}+\frac{v_{f 12}}{E_{f 1}} m_{\sigma f} \sigma_{2}\right)\right]=1-\left(10 \gamma_{21}\right)^{2}$ \\
\hline $\begin{array}{l}\text { Inter-fibre failure mode A } \\
\text { (for transverse tension) }\end{array}$ & $\sqrt{\left(\frac{\tau_{12}}{S_{12}}\right)^{2}+\left(\rho_{\perp \|}^{(+)} \frac{Y_{T}}{S_{21}}\right)^{2}+\left(\frac{\sigma_{2}}{Y_{T}}\right)^{2}+\rho_{\perp \|}^{(+)} \frac{\sigma_{2}}{S_{12}}=1-\frac{\sigma_{1}}{\sigma_{1 D}}}$ \\
\hline $\begin{array}{l}\text { Inter-fibre failure mode B } \\
\text { (for moderate transverse compression) }\end{array}$ & $\frac{1}{S_{21}}\left(\sqrt{\tau_{21}^{2}+\left(\rho_{\perp \|}^{(-)} \sigma_{2}\right)^{2}}\right)+\rho_{\perp \|}^{(-)} \sigma_{2}=1-\frac{\sigma_{1}}{\sigma_{1 D}}$ \\
\hline $\begin{array}{l}\text { Inter-fibre failure mode C } \\
\text { (for large transverse tension) }\end{array}$ & {$\left[\left(\frac{\tau_{21}}{2\left(1+\rho_{\perp \perp}^{(-)}\right) S_{21}}\right)^{2}+\left(\frac{\sigma_{2}}{Y_{C}}\right)^{2}\right] \frac{Y_{C}}{\left(-\sigma_{2}\right)}=1-\frac{\sigma_{1}}{\sigma_{1 D}}$} \\
\hline
\end{tabular}


Table 3: Zinoviev failure criteria

\begin{tabular}{|l|l|}
\hline Longitudinal tension failure & $\sigma_{1}=X_{T}$ \\
\hline Longitudinal compressive failure & $\sigma_{1}=X_{C}$ \\
\hline Transverse tensile failure & $\sigma_{2}=Y_{T}$ \\
\hline Transverse compressive failure & $\sigma_{2}=X_{C}$ \\
\hline In-plane shear failure & $\tau_{12}=S_{12}$ \\
\hline
\end{tabular}


Table 4: SSA Sandwich Panel Production Model [27]

\begin{tabular}{|l|c|}
\hline Action & Cost $(\mathrm{mins})$ \\
\hline Fairing Compound & 10 minutes $/ \mathrm{m}^{2}$ \\
\hline Smoothing Fairing Compound & 60 minutes $/ \mathrm{m}^{2}$ \\
\hline Apply Release Compound & 10 minutes $/ \mathrm{m}^{2} / \mathrm{ply}$ \\
\hline Cutting cloth & 10 minutes $/ \mathrm{m}^{2} / \mathrm{ply}$ \\
\hline Laying cloth & 5 minutes $/ \mathrm{m}^{2} / \mathrm{cloth}$ \\
\hline Cutting and laying core & 60 minutes $/ \mathrm{m}^{2} / \mathrm{core}$ \\
\hline Apply resin with brush or rollers & 10 minutes $/ \mathrm{m}^{2}$ \\
\hline Remove the components from the mould & 30 minutes $/ \mathrm{m}^{2}$ \\
\hline Quality Inspection & 3 minutes $/ \mathrm{m}^{2}$ \\
\hline Trim & 15 minutes $/ \mathrm{m} / \mathrm{edge}$ \\
\hline
\end{tabular}


Table 5: SSA Production Model

\begin{tabular}{|l|c|}
\hline Action & Cost $(\mathrm{mins})$ \\
\hline Cutting cloth & 10 minutes $/ \mathrm{m}^{2} / \mathrm{ply}$ \\
\hline Laying cloth & 5 minutes $/ \mathrm{m}^{2} / \mathrm{cloth}$ \\
\hline Cutting and laying core & 60 minutes $/ \mathrm{m}^{2} /$ core \\
\hline Apply resin with brush or roll & 10 minutes $/ \mathrm{m}^{2}$ \\
\hline
\end{tabular}


Table 6: Constant costs throughout production

\begin{tabular}{|c|c|}
\hline Quantity & Cost $£ / \mathrm{kg}$ \\
\hline E-glass Fibre & 2 \\
\hline Carbon Fibre & 15 \\
\hline High Modulus Carbon Fibre & 30 \\
\hline Aramid & 10 \\
\hline Epoxy & 20 \\
\hline Vinylester & 5 \\
\hline
\end{tabular}


Table 7: Validation of Navier method grillage analysis - Stress

\begin{tabular}{|c|c|c|c|}
\hline Property & Clarkson [1] & Maneepan et al. [20] & Current \\
\hline Deflection & $9.63 \mathrm{~mm}$ & $9.93 \mathrm{~mm}$ & $9.87 \mathrm{~mm}$ \\
\hline Stress & $165.52 \mathrm{MPa}$ & $171.19 \mathrm{MPa}$ & $170.13 \mathrm{MPa}$ \\
\hline
\end{tabular}


Table 8: Validation of Navier method grillage analysis - Shear Stress

\begin{tabular}{|c|c|c|c|}
\hline Property & $\begin{array}{c}\text { Datoo [3] } \\
(\mathrm{MPa})\end{array}$ & $\begin{array}{c}\text { Maneepan et al. [20] } \\
(\mathrm{MPa})\end{array}$ & $\begin{array}{c}\text { Current } \\
(\mathrm{MPa})\end{array}$ \\
\hline$\tau_{1}$ & 99 & 98.72 & 98.72 \\
\hline$\tau_{2}$ & 101 & 102.76 & 102.76 \\
\hline
\end{tabular}


Table 9: Validation of TSDT

\begin{tabular}{|c|c|c|}
\hline $\mathrm{L} / \mathrm{t}$ & $\operatorname{Reddy}\left(\bar{w} \times 10^{2}\right)$ & TSDT $\left(\bar{w} \times 10^{2}\right)$ \\
\hline 10 & 1.0219 & 1.0102 \\
\hline 20 & 0.7572 & 0.7546 \\
\hline 100 & 0.6697 & 0.6696 \\
\hline
\end{tabular}


Table 10: Genetic Algorithm Constraints

\begin{tabular}{|c|c|c|c|}
\hline Property & Bounds & Property & Bounds \\
\hline Long. Stiffener Spacing & $0-10230 \mathrm{~mm}$ & Ply Angles & 0,90 \\
\hline Trans. Stiffener Spacing & $0-2046 \mathrm{~mm}$ & Ply Materials & E-glass, Aramid, Carbon, HM Carbon \\
\hline Number of Plies & $0-32$ & Long. Crown Width & $0-102.3 \mathrm{~mm}$ \\
\hline Long. Crown Thickness & $0-20.46 \mathrm{~mm}$ & Long. Web Thickness & $0-20.46 \mathrm{~mm}$ \\
\hline Long. Web Height & $0-102.3 \mathrm{~mm}$ & Trans. Crown Width & $0-102.3 \mathrm{~mm}$ \\
\hline Trans. Crown Thickness & $0-20.46 \mathrm{~mm}$ & Trans. Web Thickness & $0-20.46 \mathrm{~mm}$ \\
\hline Trans. Web Height & $0-102.3 \mathrm{~mm}$ & Plate Thickness & $0-102.3 \mathrm{~mm}$ \\
\hline Stiffener Base Width & $0-102.3 \mathrm{~mm}$ & Stiffener Base Width & $0-102.3 \mathrm{~mm}$ \\
\hline
\end{tabular}


Table 11: Major Material Properties

\begin{tabular}{|c|c|c|c|c|c|}
\hline Quantity & Young's Modulus $(\mathrm{GPa})$ & Poisson's Ratio & Volume Fraction & Shear Modulus $(\mathrm{GPa})$ & Density $\left(\mathrm{kg} / \mathrm{m}^{3}\right)$ \\
\hline E-glass Fibre & 80 & 0.22 & 0.5 & 4 & 1900 \\
\hline Carbon Fibre & 175 & 0.3 & 0.6 & 5 & 1600 \\
\hline HM Carbon Fibre & 286 & 0.3 & 0.6 & 2 & 1600 \\
\hline Aramid & 131 & 0.34 & 0.6 & 1.1 & 1400 \\
\hline Epoxy & 3.0 & 0.4 & 0.4 & 1.13 & 1250 \\
\hline Vinylester & 3.4 & 0.33 & 0.5 & 1189 \\
\hline
\end{tabular}


Table 12: Stiffener Topology for First Principles Panel

\begin{tabular}{cccccc}
\hline Stiffener Type & $\begin{array}{c}\text { Web } \\
\text { Height }\end{array}$ & $\begin{array}{c}\text { Web } \\
\text { Thickness }\end{array}$ & $\begin{array}{c}\text { Crown } \\
\text { Width }\end{array}$ & $\begin{array}{c}\text { Crown } \\
\text { Thickness }\end{array}$ & $\begin{array}{c}\text { Base } \\
\text { Width }\end{array}$ \\
\hline Longitudinal & $84.1 \mathrm{~mm}$ & $3.5 \mathrm{~mm}$ & $101.1 \mathrm{~mm}$ & $5.32 \mathrm{~mm}$ & $97.4 \mathrm{~mm}$ \\
Transverse & $46.1 \mathrm{~mm}$ & $1.26 \mathrm{~mm}$ & $101.1 \mathrm{~mm}$ & $9.16 \mathrm{~mm}$ & $102.6 \mathrm{~mm}$ \\
\hline
\end{tabular}


Table 13: Plate Topology for First Principles Panel

\begin{tabular}{lcccc}
\hline & $\begin{array}{c}\text { Longitudinal } \\
\text { Stiffener Spacing }\end{array}$ & $\begin{array}{c}\text { Transverse } \\
\text { Stiffener Spacing }\end{array}$ & $\begin{array}{c}\text { Plate } \\
\text { Thickness }\end{array}$ & $\begin{array}{c}\text { Composite } \\
\text { Layup }\end{array}$ \\
\hline Plate Topology & $2200 \mathrm{~mm}$ & $720 \mathrm{~mm}$ & $3.3 \mathrm{~mm}$ & $0 / 0 / 0 / 90 / 90 / 90$ \\
\hline
\end{tabular}


Table 14: Stiffener Topology for Lloyd's Register Rules

\begin{tabular}{cccccc}
\hline Stiffener Type & $\begin{array}{c}\text { Web } \\
\text { Height }\end{array}$ & $\begin{array}{c}\text { Web } \\
\text { Thickness }\end{array}$ & $\begin{array}{c}\text { Crown } \\
\text { Width }\end{array}$ & $\begin{array}{c}\text { Crown } \\
\text { Thickness }\end{array}$ & $\begin{array}{c}\text { Base } \\
\text { Width }\end{array}$ \\
\hline Longitudinal & $19.45 \mathrm{~mm}$ & $2.6 \mathrm{~mm}$ & $42.5 \mathrm{~mm}$ & $2.6 \mathrm{~mm}$ & $42.18 \mathrm{~mm}$ \\
Transverse & $82 \mathrm{~mm}$ & $6 \mathrm{~mm}$ & $44.5 \mathrm{~mm}$ & $6 \mathrm{~mm}$ & $100 \mathrm{~mm}$ \\
\hline
\end{tabular}


Table 15: Plate Topology for Lloyd's Register Rules

\begin{tabular}{lcccc}
\hline & $\begin{array}{c}\text { Longitudinal } \\
\text { Stiffener Spacing }\end{array}$ & $\begin{array}{c}\text { Transverse } \\
\text { Stiffener Spacing }\end{array}$ & $\begin{array}{c}\text { Plate } \\
\text { Thickness }\end{array}$ & $\begin{array}{c}\text { Composite } \\
\text { Layup }\end{array}$ \\
\hline Plate Topology & $212 \mathrm{~mm}$ & $222 \mathrm{~mm}$ & $5.4 \mathrm{~mm}$ & $90 / 0 / 0$ \\
\hline
\end{tabular}


Table 16: Stiffener Topology for ISO-12215

\begin{tabular}{cccccc}
\hline Stiffener Type & $\begin{array}{c}\text { Web } \\
\text { Height }\end{array}$ & $\begin{array}{c}\text { Web } \\
\text { Thickness }\end{array}$ & $\begin{array}{c}\text { Crown } \\
\text { Width }\end{array}$ & $\begin{array}{c}\text { Crown } \\
\text { Thickness }\end{array}$ & $\begin{array}{c}\text { Base } \\
\text { Width }\end{array}$ \\
\hline Longitudinal & $10 \mathrm{~mm}$ & $1.17 \mathrm{~mm}$ & $1 \mathrm{~mm}$ & $4.39 \mathrm{~mm}$ & $212.35 \mathrm{~mm}$ \\
Transverse & $161 \mathrm{~mm}$ & $5.66 \mathrm{~mm}$ & $4 \mathrm{~mm}$ & $4.03 \mathrm{~mm}$ & $212.35 \mathrm{~mm}$ \\
\hline
\end{tabular}


Table 17: Plate Topology for ISO-12215

\begin{tabular}{lcccc}
\hline & $\begin{array}{c}\text { Longitudinal } \\
\text { Stiffener Spacing }\end{array}$ & $\begin{array}{c}\text { Transverse } \\
\text { Stiffener Spacing }\end{array}$ & $\begin{array}{c}\text { Plate } \\
\text { Thickness }\end{array}$ & Layup \\
\hline Plate Topology & $386 \mathrm{~mm}$ & $232 \mathrm{~mm}$ & $10.6 \mathrm{~mm}$ & $90 / 0 / 0 / 0 / 90$ \\
\hline
\end{tabular}

